\title{
Development of Integrated Intelligent Cad System for Design of Shafts
}

\author{
Isad SARIC, Nedim PERVAN, Adil MUMINOVIC, Mirsad COLIC
}

\begin{abstract}
Integrated intelligent CAD systems (IICAD) can be developed for different purposes. The objective of this article is to emphasize the advantages of the use of IICAD systems in comparison with the classic systems. The article shows a structure of one such developed system, namely the IICADv system. This system is used for automatization of activities undertaken during the realization of certain phases of the process of designing of shafts, especially the synthesis phase. The development of a module for computation of the shaft and integration of the entire system was performed in the C\# programming language, while shaping of the shaft was performed in the CATIA system. The interlinking was performed thanks to previously modelled basic 3D models. In such way, utilizing the advanced IICADv system, the computation and shaping of the shaft is done almost instantly. The results of the use of the IICADv systems are generated final 3D models of the shaft, ready for use by numerous other applications.
\end{abstract}

Keywords: CATIA; C\#; design; integrated intelligent CAD system; shafts

\section{INTRODUCTION}

Increasing complexity of designed products, use of new technologies, methodologies and materials, require increasing computer support in the design process. As a consequence, there is a need for quality scientific approach and a better understanding of design process, using a large number of so-called engineering tools, which are software substantiated, with interaction between these tools and better cooperation between designers [1].

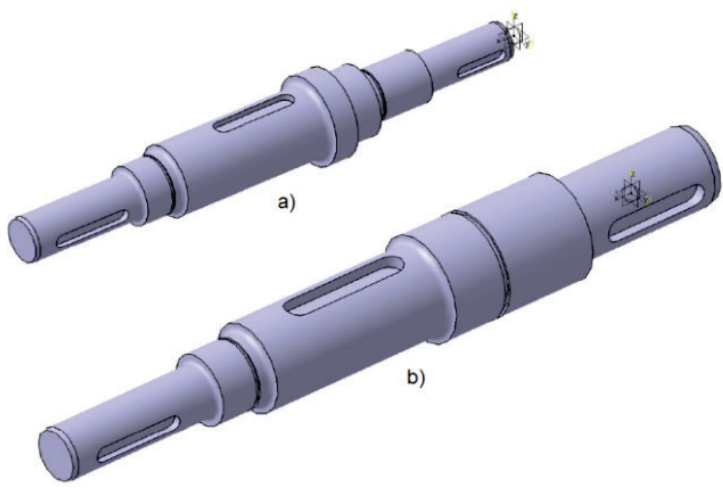

Figure 1 Shapes of analysed shafts: (a) Model 1, (b) Model 2

Contemporary designers need to be trained to work with new tools that can meet the high requirements of design agency, where the application of computers in the process of developing new products is necessary at all stages. However, it should be remembered that the traditional CAD (computer-aided design) systems mainly focused on graphical presentation, and there was not enough support to the designer. Although very widespread, benefits of these are below expectations. For many activities in the design process of products, computer support within the conventional CAD systems is not sufficiently developed. For such activities, it is possible to develop appropriate support systems. The structure of the IICADv system, developed for the purpose of the computation and shaping of the shaft (Fig. 1), is explained in this article.

Although many sophisticated CAD integrated environments have been developed and are currently adopted by enterprises in the design of mechanical parts and components, such kinds of tools should be extended in order to reach higher levels of performance [2-6].

The developed IICADv system enables you to quickly get the results of the calculations for the shaft, as well as the automatic forming of 3D geometric shaft model.

\section{IICADv SYSTEM STRUCTURE}

Development of perpetrators function of mechanical systems is based primarily on modern methods of designing, where after the conclusion of clearly defined stages, the optimum design solutions are selected. Efficient selection of the optimal design solutions taking into account compliance with all the requirements in terms of price perpetrators function, production, operation and recycling, is possible using modern $\mathrm{CAD}$ tools. The major part of the development of perpetrators function is designing to be considered in terms of material, load capacity, function, technology, recycling and application of standards [1].

The developed IICADv system actually represents KBS, meaning ES system, based on knowledge. The knowledge on design is integrated into the system through applying the techniques of artificial intelligence. With the assistance of a computer, the system enables users to automatically conduct certain activities during the realization of the process of design of the shaft. In order for these activities to be conducted as fast as possible and with quality, during system development maximum attention was paid to the integration of standards related to data processing and data exchange. The structure of a developed IICADv system is shown in Fig. 2.

Designing and writing programming code of system has been done in C\# programming language in Microsoft's programming environment Visual Studio (Fig. 3a). Installation of the IICADv system is quite simple. The system is intended for computers working on Windows operating systems. After installation, it occupies only several dozens of MB of memory space on the computer's hard disc drive. The interface layout of IICADv system, after starting the program, is presented in Fig. $3 \mathrm{~b}$.

A developed system includes four segments, intended for providing of input data, computation and presentation 
of results, generation of a detailed report on computation and generation of final 3D models.

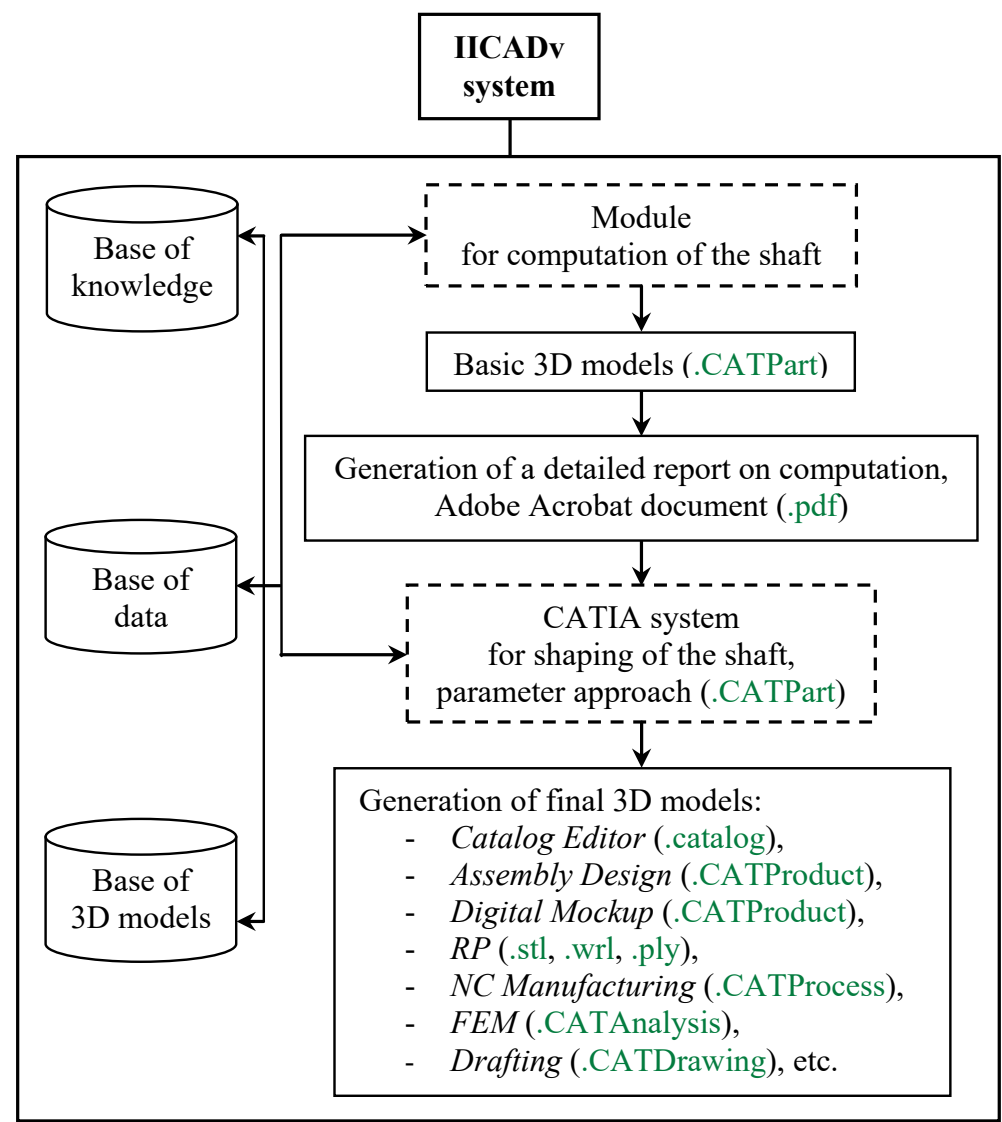

Figure 2 The structure of a developed IICADv system

double P1 = Math $\cdot \operatorname{Abs}(\mathrm{P} 3-\mathrm{P} 5) ; / /[\mathrm{W}]$

double M01 = P1 / Omega; // [Nm]

double M03 = P3 / Omega; // [Nm]

double M05 = P5 / Omega; // $[\mathrm{Nm}]$

double $\mathrm{F} 03=(2 * \mathrm{M} 03) /(\mathrm{D} 3) ; / /[\mathrm{N}]$

double $\mathrm{FO3h}=\mathrm{F03} *$ (Math.Sin $(\mathrm{Alfa} *$ Math.PI / 180));

double $\mathrm{FO3V}=\mathrm{F03} *$ (Math. $\mathrm{Cos}(\mathrm{Alfa} *$ Math.PI / 180));

double $\mathrm{Fr} 3=\mathrm{F03} *$ (Math. $\operatorname{Tan}(20 *$ Math.PI / 180)); //[N]

double $\mathrm{Fr} 3 \mathrm{~h}=\mathrm{Fr} 3 *$ (Math. $\mathrm{Cos}(\mathrm{Alfa} *$ Math. PI / 180));

double $\mathrm{Fr3v}=\mathrm{Fr} 3 *$ (Math.Sin(Alfa * Math.PI / 180));

double $\mathrm{F} 05=(2 * \mathrm{M} 05) / \mathrm{D} 5 ; / /[\mathrm{N}]$

double $\mathrm{Fk}=2 * \mathrm{~F} 05 ; / /[\mathrm{N}]$

double $\mathrm{Fkh}=\mathrm{Fk} *$ Convert. ToDouble (Math.Cos(Beta * Math.PI / 180));

double $\mathrm{Fkv}=\mathrm{Fk} *$ Convert. ToDouble(Math.Sin(Beta * Math.PI / 180));

a)

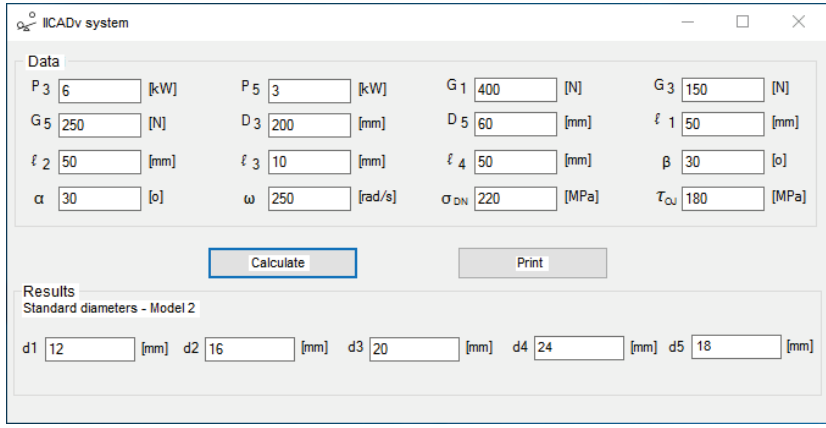

b)

Figure $3 \mathrm{C \#}$ code and interface layout of IICADv system: (a) part of C\# code, (b) interface layout after starting the program

\section{MATHEMATICAL MODEL OF SHAFT}

The input power to the shaft is through a gear which is located "in the middle" of the shaft, and the output power is through the pulley and coupling which are located at the ends of the shaft. Since the power at the place of the gear $\left(P_{3} / \mathrm{kW}\right)$ and pulley $\left(P_{5} / \mathrm{kW}\right)$ is known, one can determine the power at the place of coupling $\left(P_{1} / \mathrm{kW}\right)$, Eq. (1).

$$
P_{1}=P_{3}-P_{5} / \mathrm{kW}
$$

After the value of the power at the characteristic places of the shaft is known, with the knowledge of angular velocity of the shaft ( $\omega / \mathrm{rad} / \mathrm{s})$, torques at those same places can be determined, Eq. (2).

$$
M_{o 1}=\frac{P_{1}}{\omega} / \mathrm{Nmm}, M_{o 3}=\frac{P_{3}}{\omega} / \mathrm{Nmm}, M_{o 5}=\frac{P_{5}}{\omega} / \mathrm{Nmm}
$$

In addition to determining the bending moments $\left(M_{s i}\right.$ $/ \mathrm{Nmm}$ ) on the shaft and the known value of torque, we can determine the ideal moments $\left(M_{i i} / \mathrm{Nmm}\right)$ which are important for determining the diameter of the shaft at the characteristic places, Eq. (3),

$M_{i i}=\sqrt{M_{s i}^{2}+\left(\frac{\sigma_{d s}}{2 \tau_{d u}} M_{u i}\right)^{2}} / \mathrm{Nmm}$

where is: 
$\sigma_{d s} / \mathrm{MPa}$-allowable stress to bending of the shaft material,

$\tau_{d u} / \mathrm{MPa}$-allowable stress on torsion of the shaft material.

Finally, after determining the ideal moment, the shaft diameters are determined, Eq. (4),

$d_{i i}=\sqrt[3]{\frac{10 M_{i i}}{\sigma_{d}}} / \mathrm{mm}$

where is:

$\sigma_{d} / \mathrm{MPa}-$ allowable stress of the shaft [7].

Based on the diameter of the shaft, dimensions of grooves at the places of gear, pulley and coupling are determined and adopted, as well as dimensions of grooves for Seeger's ring at the places of sleeve shaft.

\section{PARAMETRIC DESIGN OF SHAFT}

The term parametric design associated with parametric systems is defined as "a process of designing with parametric models in a virtual surrounding where geometrical and parameter variation are natural" [8].

Advantage of parametric design is dimensional and shape flexibility of the modelled part of introduction into the different assemblies. The biggest advantage of this type of modelling is reflected in the possibility of a rapid change in size, shape and position of the modelled elements [9-11]. Lack of parametric modelling is reflected in the need to invest more time and effort in the process of modelling elements, but the time and effort of multiple payments in phases of assembly designing must also be emphasized. The first step is the creation of 2D sketches of shaft, which is the basis for creating of $3 \mathrm{D}$ models (Fig. 4). [12, 13]

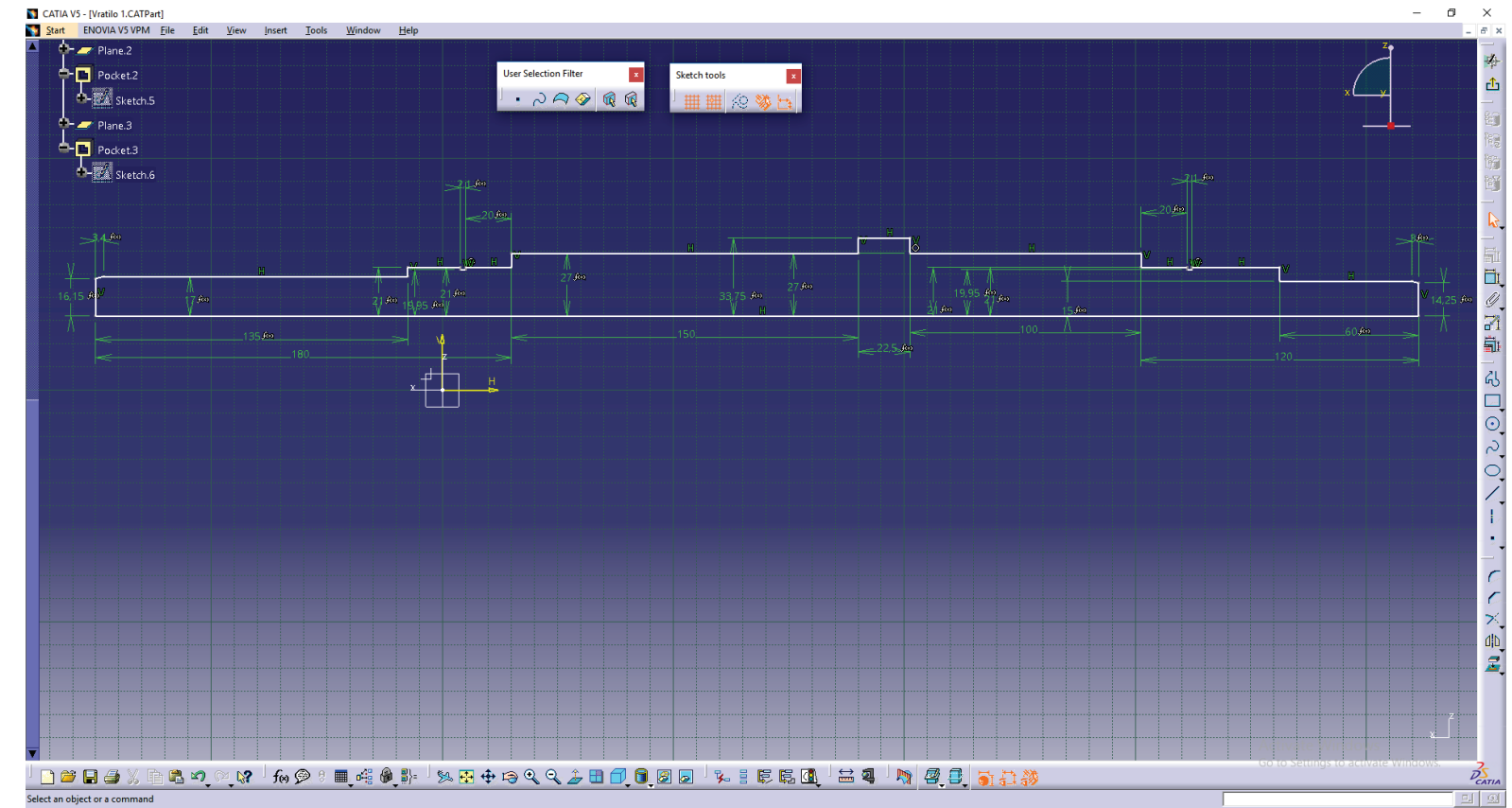

Figure 4 2D sketch of shaft (Model 1) in the Sketcherworkbench

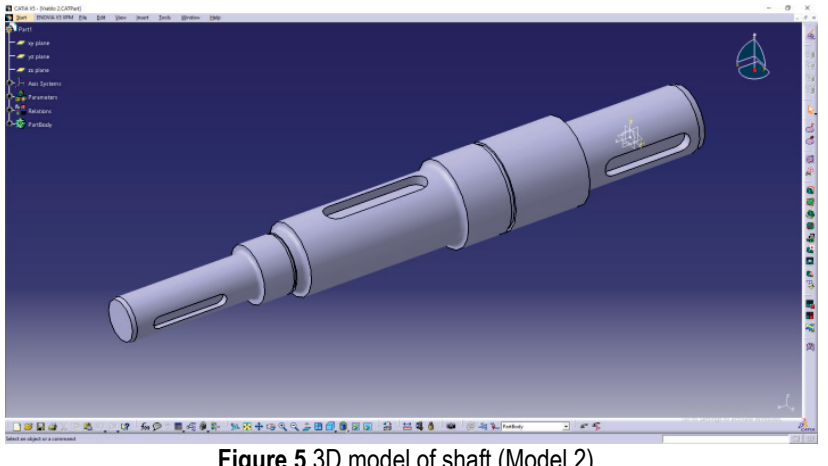

Figure 5 3D model of shaft (Model 2)

After formation of the 3D model of shaft, it is necessary to form grooves at places where there are elements of power transmission (couplings, gears, pulleys). With the creation of grooves on the shaft, the modelling process of shaft is finished, and we have two types of shafts (Fig. 5 shows the Model 2).

After formation of the 3D model, it is necessary to perform parameterization of models that could be connected to the IICADv system. In the first step of parameterization, it is necessary to rename all sizes in Sketchers (i.e. forming geometrical parameters) so that it can automatically connect with the parameters in table of parameters.

Parameters which are formed on the 3D model of shaft include diameters $d_{1} \div d_{5}$ and the characteristic length of shaft $l_{1} \div l_{4}$ (Fig. 6a). After formed parameters, it is necessary to form a relation of all dimensions on the shaft, which will be correlated with diameters of the shaft (Fig. 6b).

After defining the parameters and relations based on which the geometric relationships are calculated, parameterization process ends with the formation of parameter tables. During the formation of the table, option Create a design table from a pre-existing file is selected, and the table in CATIA connects to Excel table which is previously formed and in which the values of certain diameter and length of the shaft are automatically entered from IICADv system. 


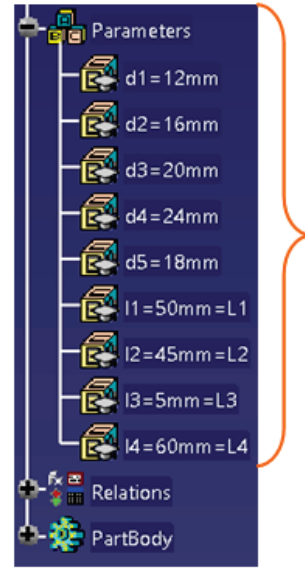

custumer parameters set used for control of parameter shaft geometry control

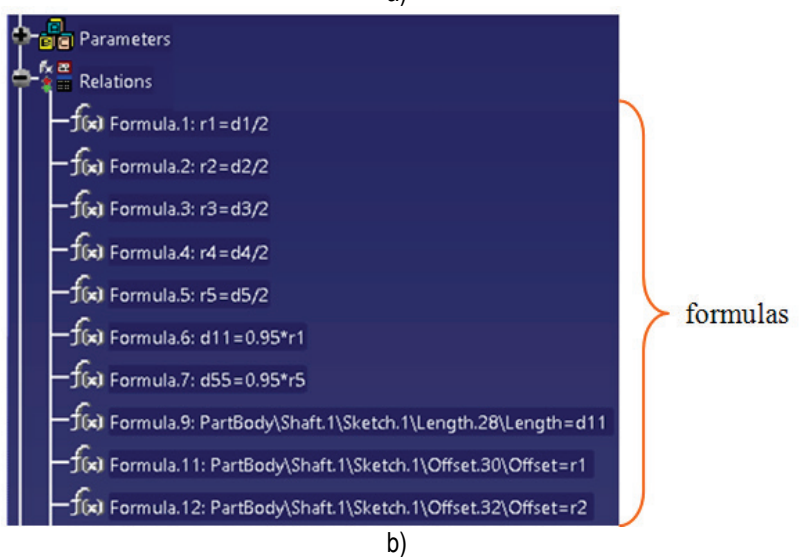

Figure 6 Parameters (a) and relations (b) used for shaft geometry control

\section{EXPERIMENTAL TESTING OF IICADv SYSTEM}

During development, the intention was that the IICADv system can be easily linked to RP devices working on the principle of additive technologies [14] and CNC machines operating on the principle of numeric control. Therefore, a developed system enables a quick and simple construction of physical prototypes and final functional parts.

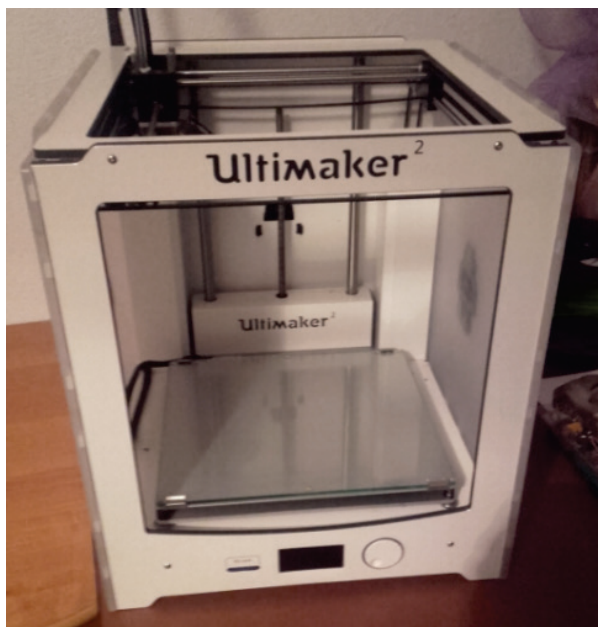

Figure 7 3D printer Ultimaker 2

Evaluation of a developed IICADv system was performed, among other, through construction of physical prototypes on a RP device and $\mathrm{CNC}$ machine. A basis for construction of physical prototypes were the resulting $3 \mathrm{D}$ models generated from the IICADv system.
Physical prototypes of shafts were printed in organic plastic PLA on a 3D printer Ultimaker 2 (Fig. 7), produced by the Dutch company with the same name.

The RP technologies, through the physical model of a product, enable an analysis of the product functionality within the assembly, checking of design, ergonomic analysis and other functional testings [15]. Used in various industrial fields, RP facilitates the evaluation of geometry, as well as check on manufacturability and other functional testing. Because RP is based on the 3D CAD model, it can be effectively combined with the concept of concurrent engineering. $[16,17]$

The resulting 3D models of shafts generated from the IICADv system are processed before printing in Cura software, which regulates the operation of $3 \mathrm{D}$ printer (Fig. $8)$.

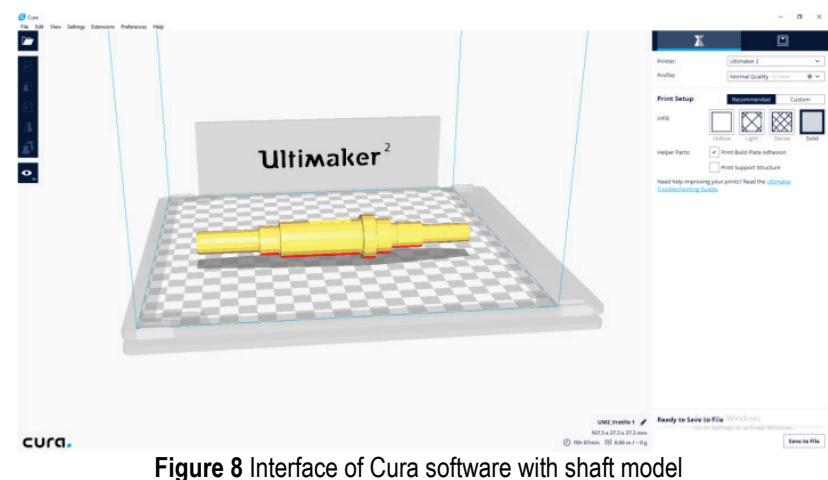

Physical prototypes of shafts were made of construction steel E335 on a universal CNC lathe TRAUB TNA400 (Fig. 9), produced by the German company with the same name.

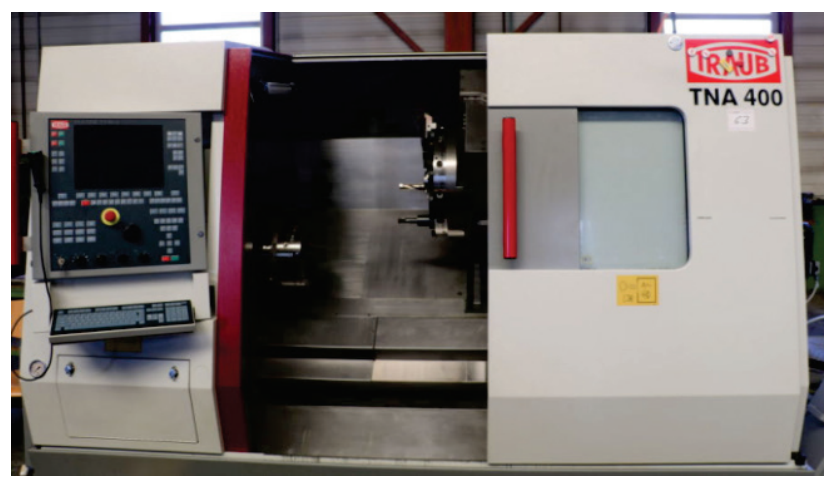

Figure 9 Universal CNC turning machine TRAUB TNA400

The resulting 3D models of shafts generated from the IICADv system are processed before turning with a standard post-processor that regulates the operation of CNC lathe (Fig. 10).

Fig. 11 shows the resulting 3D models generated from the IICADv system, physical prototypes printed on 3D printer, as well as physical prototypes constructed on CNC lathe. 

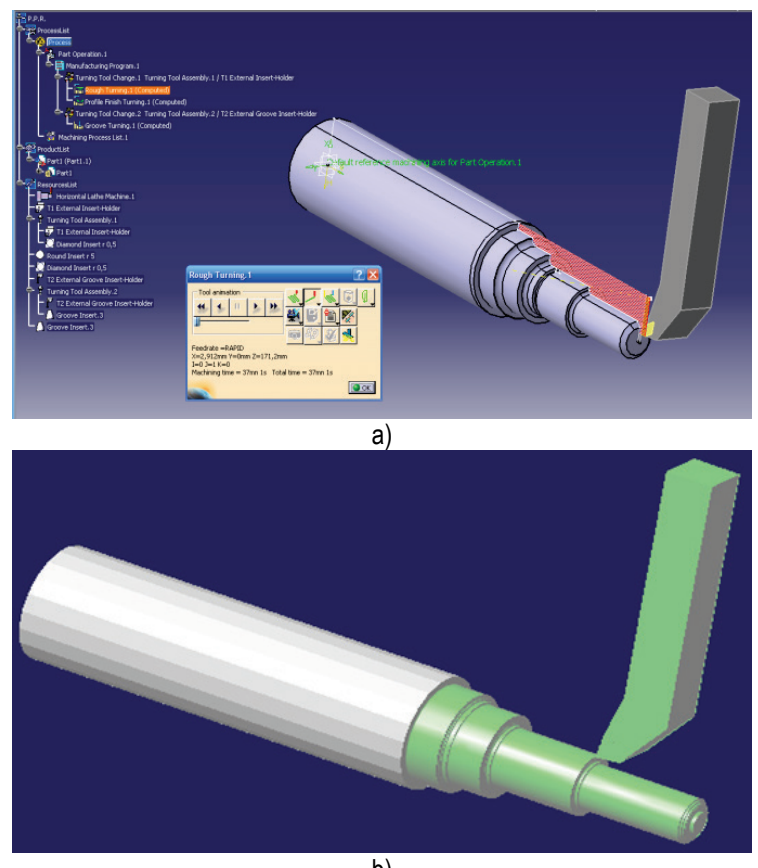

b)

Figure 10 Simulation of trajectory of movement of tools (a) and 3D simulation of processing by turning (b) during construction of physical prototypes of shafts on CNC lathe

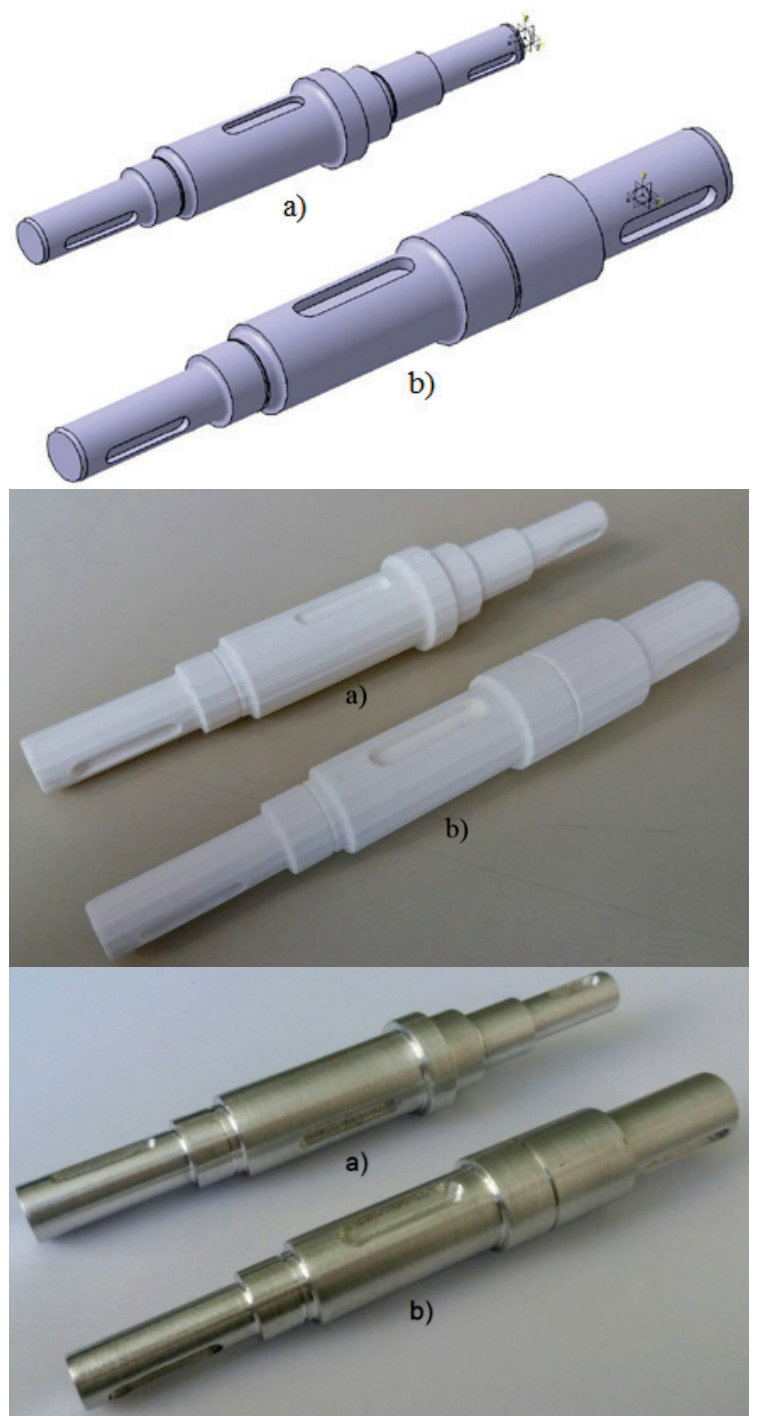

Figure 11 Resulting 3D models of shafts generated from the IICADv system and physical prototypes printed on 3D printer, as well as physical prototypes constructed on CNC lathe: (a) Model 1, (b) Model 2

\section{CONCLUSION}

The traditional sequential and non-intelligent approach to design is exhausting and expensive, and it does not help much with the optimization of the process of design and production $[1,9]$.

A developed IICADv system unifies the functional requirements necessary for support to the designer during integrated intelligent designing of shaft, while in the same time establishing a direct link with: analytical computation, parameter $3 \mathrm{D}$ models based on production features, RP devices, CNC machines, etc.

Therefore, a developed integrated intelligent environment provides information for faster and more quality decision-making during the process of design. The IICADv system enables quick acquiring of results of computation of shaft, as well as automatic generation of final 3D models of shafts, which are a basis for utilization of numerous other applications. Thus, the positive effects of its application in comparison with the existing conventional systems are visible, especially taking into account the time required for design, which is significantly shorter, and the quality of the product, which is significantly higher.

For the reasons stated above, the development of such or similar integrated intelligent CAD systems is absolutely justifiable, and a more intensive application of the socalled distributed hybrid web-based integrated intelligent systems of design should be expected in the future.

Finally, it should be emphasized that the shown general methodology of integrated intelligent design is applicable regardless of the type of product or industry.

\section{REFERENCES}

[1] Saric, I. (2014). Development of Integrated CAD System for Design of Mechanical Power Transmissions. Doctoral Dissertation, Faculty of Mechanical Engineering Sarajevo, Sarajevo, September 2014.

[2] Colombo, G., Mosca, A., \& Sartori, F. (2007). Towards the design of intelligent CAD systems: An ontological approach. Advanced Engineering Informatics, 21(2), 153-168. https://doi.org/10.1016/j.aei.2006.11.003

[3] Liao, Y. H., Liu, G. J., \& Sun, X. G. (2014). Development of an Intelligent CAD System for Involute Cylindrical Gear Cutting Tools. Applied Mechanics and Materials, 532, 249252. https://doi.org/10.4028/www.scientific.net/AMM.532.249

[4] Mwinuka, T. E. \& Mgwatu, M. I. (2015). Tool selection for rough and finish CNC milling operations based on tool-path generation and machining optimisation. Advances in Production Engineering \& Management, 10(1), 18-26. https://doi.org/10.14743/apem2015.1.189

[5] Klancnik S., Brezocnik M., \& Balic J. (2016). Intelligent $\mathrm{CAD} / \mathrm{CAM}$ System for Programming of CNC Machine Tools. International Journal of Simulation Modelling, 15(1), 109-120. https://doi.org/10.2507/IJSIMM15(1)9.330

[6] Xu, T., Chen, Z., Li, J., \& Yan, X. (2015). Automatic tool path generation from structuralized machining process integrated with $\mathrm{CAD} / \mathrm{CAPP} / \mathrm{CAM}$ system. The International Journal of Advanced Manufacturing Technology, 80(5-8), 1097-1111. https://doi.org/10.1007/s00170-015-7067-5

[7] Repcic, N.; Muminovic, A. (2007). Mechanical Elements II. Faculty of Mechanical Engineering Sarajevo, Sarajevo. 
[8] Bodein, Y., Rose, B., \& Caillaud, E. (2014). Explicit reference modeling methodology in parametric CAD system. Computers in Industry, 65(1), 136-147. https://doi.org/10.1016/j.compind.2013.08.004

[9] Saric, I., Muminovic, A., Colic, M., \& Rahimic, S. (2017). Development of integrated intelligent computer-aided design system for mechanical power-transmitting mechanism design. Advances in Mechanical Engineering, 9(7), 1-16. https://doi.org/10.1177/1687814017710389

[10] Novak, M. \& Dolšak, B. (2000). An Intelligent Computer System for Supporting Design Education. Strojniški vestnik - Journal of Mechanical Engineering, 46(6), 383-390.

[11] Wang, S.-H., Melendez, S., \& Tsai, C.-S. (2008). Application of Parametric Sketching and Associability in 3D CAD. Computer-Aided Design \& Applications, 5(6), 822830. https://doi.org/10.3722/cadaps.2008.822-830

[12] Karayel, D., Ozkan, S. S., \& Vatansever, F. (2013). Integrated Knowledge-Based System for Machine Design. Advances in Mechanical Engineering, 5, 1-10. https://doi.org/10.1155/2013/702590

[13] Lee, C. K. M., Lau, H. C. W., \& Yu, K. M. (2005). An objectbased knowledge integration system for product development: A case study. Journal of Manufacturing Technology Management, 16(2), 156-177. https://doi.org/10.1108/17410380510576813

[14] Camburn, B., Dunlap, B., Gurjar, T., et al. (2015). A Systematic Method for Design Prototyping. Journal of Mechanical Design, 137(8), pp. 081102. https://doi.org/10.1115/1.4030331

[15] Mandić, V. \& Ćosić, P. (2011). Integrated product and process development in collaborative virtual engineering environment. Tehnicki vjesnik-Technical Gazzete, 18(3), 369-378.

[16] Park, K., Kim, Y. S., Kim, C. S., Park, H. J. (2007). Integrated application of $\mathrm{CAD} / \mathrm{CAM} / \mathrm{CAE}$ and $\mathrm{RP}$ for rapid development of a humanoid biped robot. Journal of Materials Processing Technology, 187-188, 609-613. https://doi.org/10.1016/j.jmatprotec.2006.11.147

[17] Yang, D. Y., Ahn, D. G., Lee, C. H., Park, C. H., \& Kim, T. J. (2002). Integration of $\mathrm{CAD} / \mathrm{CAM} / \mathrm{CAE} / \mathrm{RP}$ for the development of metal forming process. Journal of Materials Processing Technology, 125-126, 26-34.

https://doi.org/10.1016/S0924-0136(02)00414-4

\section{Contact information:}

Isad SARIC, Assist. Prof. Dr.

University of Sarajevo,

Faculty of Mechanical Engineering,

Department of Mechanical Design

Vilsonovo setaliste 9, 71000 Sarajevo, Bosnia and Herzegovina

E-mail: saric@mef.unsa.ba

Nedim PERVAN, Senior Assist

University of Sarajevo,

Faculty of Mechanical Engineering

Department of Mechanical Design

Vilsonovo setaliste 9,71000 Sarajevo, Bosnia and Herzegovina

E-mail: pervan@mef.unsa.ba

Adil MUMINOVIC, Full Prof. Dr

University of Sarajevo,

Faculty of Mechanical Engineering

Department of Mechanical Design

Vilsonovo setaliste 9, 71000 Sarajevo, Bosnia and Herzegovina

E-mail: muminovic@mef.unsa.ba

Mirsad COLIC, Assoc. Prof. Dr.

University of Sarajevo,

Faculty of Mechanical Engineering,

Department of Mechanical Design

Vilsonovo setaliste 9,71000 Sarajevo, Bosnia and Herzegovina

E-mail: colic@mef.unsa.ba 